\title{
Изменение проводимости полианилиновых нанотрубок в процессе их формирования
}

\author{
(C) В.М. Капралова ${ }^{1}$, И.Ю. Сапурина ${ }^{2}$, Н.Т. Сударь \\ ${ }^{1}$ Санкт-Петербургский политехнический университет Петра Великого \\ 195251 Санкт-Петербург, Россия \\ ${ }^{2}$ Институт высокомолекулярных соединений Российской академии наук, \\ 199004 Санкт-Петербург, Россия \\ I E-mail: sudar53@mail.ru
}

(Получена 26 октября 2017 г. Принята к печати 15 ноября 2017 г.)

Показано, что способ выращивания проводящих полианилиновых нанотрубок, основанный на прямой полимеризации анилина на поверхности каналов трековых мембран, может быть использован для создания нанотрубок с заданной проводимостью. Установлено, что на начальной стадии полимеризации (до 2 мин) в трековом канале формируется пленка островкового типа и сопротивление канала $\sim 10^{19}$ Ом. Увеличение времени полимеризации до 3 мин приводит к уменьшению сопротивления канала на 10 порядков, что обусловлено формированием сплошной пленки на его поверхности, т. е. формированием нанотрубки. При увеличении времени полимеризации сопротивление канала (нанотрубки) плавно уменьшается. Удельная проводимость полианилина при формировании полой нанотрубки оценивается в $0.01-0.04$ См/см. При полном заполнении нанотрубки полианилином она возрастает до $\sim 0.2 \mathrm{Cm} / \mathrm{cm}$.

DOI: $10.21883 /$ FTP.2018.06.45934.8756

\section{1. Введение}

В настоящее время наноструктурированный полианилин (ПАНИ) и композиционные материалы на его основе, обладающие полупроводниковыми свойствами, находят широкое применение при создании различного рода электронных устройств. ПАНИ используется для экранирования электромагнитного излучения, он входит в состав электродных материалов аккумуляторных батарей и конденсаторов, применяется в качестве антистатика и электрохромного агента. В последние годы большое внимание стало уделяться созданию и изучению наноструктур этого полимера, в частности нанотрубок $[1,2]$. Уже сейчас полианилиновые нанотрубки нашли практическое применение при создании суперконденсаторов [3], сенсорных устройств и полимерных солнечных ячеек [4-6].

Известны различные способы создания полианилиновых нанотрубок [1]. Технологически одним из наиболее простых является синтез нанотрубок посредством выращивания пленок полианилина на поверхности каналов трековых полимерных мембран с последующим растворением материала мембраны и осаждением нанотрубок [7]. В этом случае диаметр нанотрубки определяется диаметром трекового канала, а ее длина - длиной трека в мембране. Разработка высокотехнологичных in situ методов получения наноструктурированного ПАНИ $[8,9]$ позволяют синтезировать нанотрубки не только определенного диаметра и длины, но и варьировать толщину стенок нанотрубки. Очевидно, морфология нанотрубки и ее электрофизические свойства изменяются в процессе синтеза полианилина и формирования пленки ПАНИ на стенках трекового канала. Изучение закономерностей изменения электрических свойств нанотрубок ПАНИ в процессе полимеризации являлось целью настоящей работы.

\section{2. Методика эксперимента}

В качестве трековой мембраны использовалась пленка полиэтилентерефталата (ПЭТФ) размером $4 \times 4$ см толщиной $12 \pm 0.5$ мкм со сквозными каналами диаметром $200 \pm 30$ нм, возникающими в полимерной пленке при ионном облучении. Объемная доля каналов (пористость) мембраны составляла около $20 \%$.

Нанесение пленки ПАНИ на поверхность каналов трековой мембраны осуществлялась методом in situ полимеризации анилина при прокачке сквозь каналы мембраны смеси растворов анилина $(0.2 \mathrm{M})$ и пероксидисульфата аммония $(0.25 \mathrm{M})$. Время полимеризации (роста пленки) определялось временем, в течение которого эта смесь прокачивалась сквозь поры мембраны. Затем реагент удалялся из каналов посредством прокачки сквозь них большого объема $0.2 \mathrm{M}$ раствора соляной кислоты. Процесс полимеризации ПАНИ прекращался. По завершении полимеризации слой ПАНИ с поверхности пленки механически удалялся ватой, смоченной в этаноле. Обработанную мембрану сушили в воздухе.

Указанным способом было обработано четыре мембраны, для которых время полимеризации анилина составляло 2, 3, 5 и 10 мин.

Затем на поверхность мембран термическим напылением в вакууме при давлении около $10^{-4}$ Па наносились золотые электроды. На нижнюю поверхность каждой мембраны наносился один электрод диаметром $2.5 \mathrm{~cm}$, а на верхнюю - 20 электродов диаметром 0.42 мм. Здесь следует отметить, что напыление золота на обе стороны 
пленки не приводило к короткому замыканию электродов, поскольку каналы при изготовлении трековой мембраны были пробиты ионами не перпендикулярно к ее поверхности. Нанесение на поверхность мембраны большого числа электродов позволяло проводить измерения сопротивления на различных участках ее поверхности. Участок пленки под одним верхним электродом рассматривался нами как отдельный образец. Результаты измерений усреднялись по всем образцам, расположенным на данной мембране.

Электрическое сопротивление образцов при сопротивлении менее 1 МОм измерялось с помощью мультиметра, а при большем сопротивлении образцов использовался электрометр Keithley.

Исследование структуры ПАНИ, выращенного на открытой поверхности пленки ПЭТФ методом in situ, проводили с помощью сканирующего электронного микроскопа Carl Zeiss Supra 55 VP, без предварительного напыления металла (золота).

\section{3. Экспериментальные результаты и их обсуждение}

Вследствие относительно большой площади верхних электродов под каждым из них могло находиться несколько трековых каналов. Эквивалентное сопротивление образца $R$ с числом трековых каналов под электродом $n$ можно представить в виде параллельно включенных сопротивлений трековых каналов с пленкой ПАНИ на стенках и параллельно подключенного к ним объемного сопротивления пленки ПЭТФ под верхним электродом $R_{\text {РЕТ }}$.

Полагая, что сопротивления всех трековых каналов одинаковы и равны $r_{\mathrm{c}}$, получим

$$
r_{\mathrm{c}}=\frac{n R_{\mathrm{PET}} R}{R_{\mathrm{PET}}-R}
$$

Так как объемная доля трековых каналов в мембране составляет $20 \%$, то

$$
n S_{\mathrm{c}}=0.2 S
$$

и

$$
R_{\mathrm{PET}}=\frac{\rho_{\mathrm{PET}} L}{0.8 S},
$$

где $S_{\mathrm{c}}-$ площадь сечения канала, $\rho_{\text {РЕт }}-$ удельное сопротивление ПЭТФ, $S$ - площадь верхнего электрода, $L$ - длина канала, примерно равная толщине пленки ПЭТФ. Подставляя (2) и (3) в (1), получим

$$
r_{\mathrm{c}}=0.2 \frac{S}{S_{\mathrm{c}}} \frac{L R \rho_{\mathrm{PET}}}{\rho_{\mathrm{PET}} L-0.8 R S} .
$$

В таблице представлены времена полимеризации и соответствующие им средние значения сопротивлений образцов с указанием погрешности измерений. На основании этих данных по формуле (4) рассчитывалось

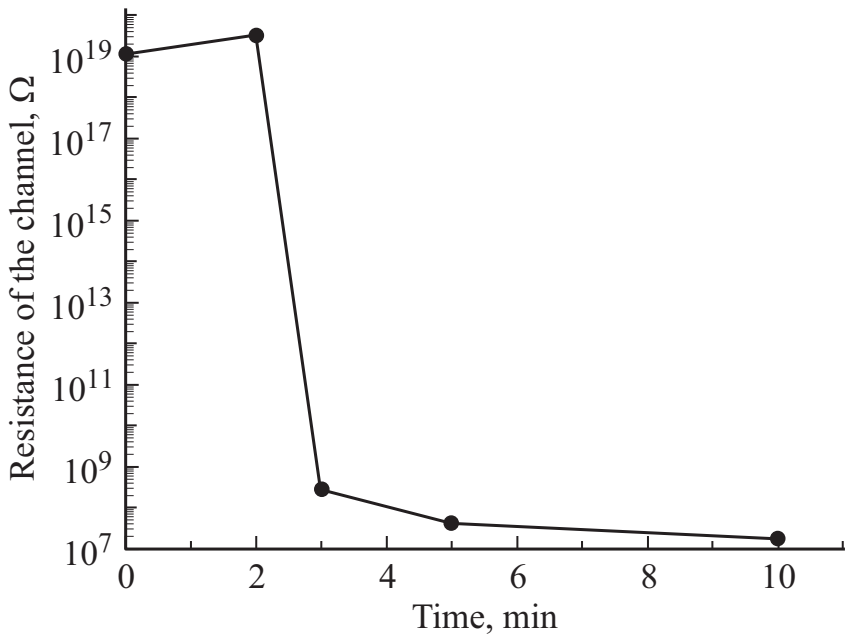

Рис. 1. Среднее значение сопротивления трекового канала с нанесенной на его поверхность пленкой ПАНИ при различных временах полимеризации.

среднее значение сопротивления трекового канала с нанесенной на его поверхность пленкой ПАНИ при различных временах полимеризации. Результаты расчетов представлены на рис. 1.

Видно, что при увеличении времени полимеризации с 2 до 3 мин наблюдается скачкообразное уменьшение сопротивления канала более чем на 10 порядков величины. Следуя данным работы [9], можно принять, что при малых временах полимеризации на поверхности трекового канала формируется пленка островкового типа, в которой отдельные островки ПАНИ не образуют единого кластера. Островком служит центр нуклеации полимера или гранула ПАНИ - частица квазисферической формы, которая увеличивает свои размеры по мере роста полимерных цепей. Толщина формируемой пленки на этом (начальном) этапе полимеризации будет определяться размером гранул, образующих нанотрубки. Начальный период заканчивается, когда формируется единый кластер из слившихся гранул, соединяющий электроды, что приводит к скачкообразному уменьшению сопротивления канала. Нанотрубку ПАНИ можно представить как слой плотно упакованных гранул, покрывающих всю внутреннюю поверхность трекового канала.

Значения времени полимеризации и соответствующие им средние величины сопротивлений образцов

\begin{tabular}{c|c}
\hline Время, мин & Сопротивление, Ом \\
\hline 0 & $(1.4 \pm 0.6) \cdot 10^{13}$ \\
2 & $(3.7 \pm 0.4) \cdot 10^{13}$ \\
3 & $(3.2 \pm 0.6) \cdot 10^{2}$ \\
5 & $(5 \pm 3) \cdot 10^{2}$ \\
10 & $(2.3 \pm 0.4) \cdot 10$
\end{tabular}


Условия синтеза в работе [9] и в настоящей работе были идентичными. Единственное отличие состояло в том, что в работе [9] пленка выращивалась в неограниченном объеме, а в настоящей работе в ограниченном объеме трекового канала. В случае, когда время полимеризации превышало 3 мин, авторы работы [9] наблюдали увеличение толщины пленочного покрытия со скоростью примерно 25 нм/мин. Примем, что и в рассматриваемой ситуации толщина пленки увеличивается с той же скоростью. Из представленной на рис. 1 зависимости следует, что при $t>3$ мин по мере увеличения времени полимеризации и соответственно увеличения толщины стенок полианилиновой нанотрубки наблюдается уменьшение ее сопротивления примерно на порядок величины. Этот результат может свидетельствовать как о формировании дополнительных проводящих путей между электродами, так и об увеличении электрической проводимости первоначально образованного пути вследствие прорастания молекул между гранулами.

Представляет интерес оценить удельную проводимость формирующейся в трековом канале полианилиновой нанотрубки.

Рассмотрим пленку ПАНИ, выросшую на поверхности канала трековой мембраны, как трубку длиной $L$ с внешним радиусом $R_{\text {c }}$ и толщиной $h$. Примем, что значение $h$ соответствует усредненной толщине пленки ПАНИ на стенках трекового канала. При сделанных допущениях удельное сопротивление $\sigma_{\mathrm{PANI}}$ можно рассчитать по формуле

$$
\sigma_{\mathrm{PANI}}=\frac{L}{r_{\mathrm{c}} \pi\left(2 R_{\mathrm{c}} h-h^{2}\right)} .
$$

Согласно работе [9], толщина пленки ПАНИ после 3 и 5 мин полимеризации составляет соответственно 25 и 75 нм. Следовательно, можно предположить, что в рассматриваемом эксперименте канал трековой мембраны будет не полностью заполнен, и образуется трубчатая структура ПАНИ. Примем эти величины в качестве толщины стенок нанотрубок и выполним расчеты проводимости по формуле (5). Получим, что значение проводимости составит $1 \cdot 10^{-2}$ и $4 \cdot 10^{-2} \mathrm{Cm} / \mathrm{cm}$. Эти величины согласуются с известными данными о проводимости нанотрубок [1]. При полимеризации в течение 10 мин ПАНИ полностью заполняет объем трекового канала, т.е. в соотношении (5) следует принять $h=R_{\mathrm{c}}$. В этом случае значение удельной проводимости возрастает до $\sim 0.2 \mathrm{Cm} / \mathrm{cm}$, что соответствует удельной проводимости сплошных пленок ПАНИ, выращенных на открытых подложках [9].

Известно, что рост пленок ПАНИ на носителе критическим образом зависит от химической структуры и свойств поверхности подложки. На гидрофобных поверхностях концентрация центров нуклеации выше, чем на гидрофильных. Она возрастает также в присутствии на носителе кислотных и эфирных групп, с которыми активно взаимодействуют олигомеры анилина. Первоначально из таких центров формируются наносферы с

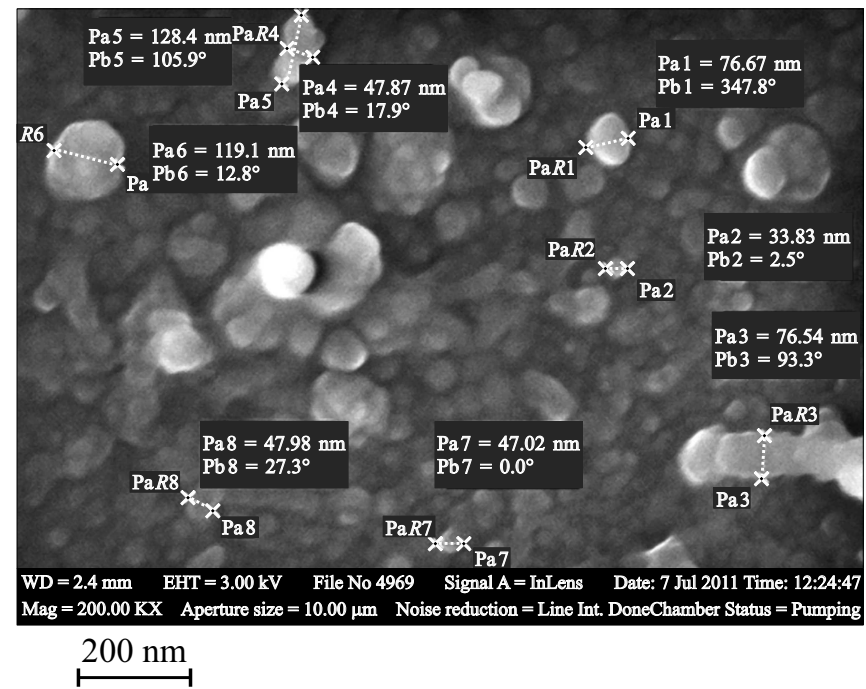

Рис. 2. Слой ПАНИ на ПЭТФ через 6 мин синтеза. Частицы с размерами 30-40 нм формируют слой наносфер, выросший непосредственно на подложке. Более крупные и светлые частицы - агрегаты ПАНИ, выросшие в объеме реакционной фазы и седиментировавшие на поверхность пленки.

унимодальным распределением по форме и размерам, диаметр которых увеличивается от единиц до десятков нанометров пропорционально продолжительности стадии роста $[10,11]$.

Таким образом, число нуклеационных центров определяется свойствами подложки и условиями синтеза и не зависит от времени полимеризации. Известно, что на поверхности кремния концентрация нуклеационных центров при полимеризации ПАНИ оценивается в $\sim 40$ мкм $^{-2}$ [12]. Концентрация нуклеационных центров на поверхности ПЭТФ до настоящего времени не была исследована. Поскольку ПЭТФ - гидрофобный материал, к тому же макромолекулы ПЭТФ содержат эфирные группы, следовало ожидать большей концентрации нуклеационных центров.

Данные электронной микроскопии (рис. 2) показывают, что при 6 мин синтеза наносферы уже покрывают всю поверхность ПЭТФ. Если подвижность наносфер не ограничена контактом с поверхностью, то они группируются в квазисферические образования (гранулы) субмикронных размеров. Толщина полимерного слоя приближенно соответствует диаметру гранулы. Дальнейшей агломерации ПАНИ препятствует связь полимера с поверхностью [11]. Однако толщина пленки ПАНИ на поверхности ПЭТФ, а следовательно, и толщина стенок нанотрубки ПАНИ могут продолжать увеличиваться за счет агрегатов ПАНИ, выросших в объеме реакционной фазы и седиментировавших на поверхность стенок. В результате ПАНИ заполнит весь объем канала.

Учитывая вышеизложенное, можно предположить, что наблюдаемое нами резкое изменение сопротивления формирующейся пленки при увеличении времени по- 
лимеризации обусловлено перколяционным эффектом. Он возникает, когда наносферы, формирующиеся на поверхности трекового канала, соприкасаются и образуют проводящий канал, соединяющий электроды. Представляется, что данная ситуация наиболее близка к задаче окружностей теории протекания [13], согласно которой критерий перколяции определяется соотношением

$$
B=\pi k r^{2}
$$

где $B=4.1 \pm 0.4, k$ и $r-$ концентрация окружностей и их радиус.

Применительно к рассматриваемой ситуации под $\mathrm{r}$ следует понимать радиус полусферы, внутрь которой вписана наносфера. Если принять, что $k=40$ мкм $^{-2}$, то радиус наносферы составит $\sim 180$ нм. Оценим возможную концентрацию активных центров на пленке ПЭТФ, при которой радиус агломерата, определяющий толщину пленки, составит 30 нм. Воспользовавшись соотношением (6), получим $k \approx 1500$ мкм $^{-2}$, т. е. среднее расстояние между наносферами составит $\sim 30 \mathrm{нм}$.

\section{4. Заключение}

Таким образом, использование метода прямой полимеризации анилина на поверхности каналов трековой мембраны позволяет установить характер изменения проводимости полианилиновой нанотрубки в процессе ее формирования. Данный метод открывает принципиальную возможность создания полианилиновых нанотрубок с заданной проводимостью. Можно говорить о трех стадиях формирования полианилиновых нанотрубок.

На первой стадии, при времени полимеризации менее 3 мин, на стенках трекового канала вырастает пленка ПАНИ островкового типа, в которой отдельные островки ПАНИ не образуют единого кластера. Сопротивление трекового канала на этой стадии составляет $\sim 10^{19}$ Ом.

Вторая стадия формирования нанотрубок ПАНИ соответствует временно́му интервалу от 3 до 5 мин. Переход от первой ко второй стадии соответствует быстрому уменьшению сопротивления трекового канала более чем на 10 порядков величины. На второй стадии наблюдается достаточно плавное уменьшение сопротивления трекового канала, что обусловлено увеличением толщины стенок формирующейся нанотрубки. Варьирование времени полимеризации на этой стадии формирования нанотрубок позволяет создавать полианилиновые нанотрубки с заданной проводимостью.

Третья стадия формирования нанотрубок соответствует времени полимеризации более 5 мин. На этой стадии нанотрубка диаметром $\sim 200$ нм полностью заполняется ПАНИ и ее удельная проводимость оказывается сопоставимой с проводимостью сплошных пленок ПАНИ, выращенных на открытых подложках.

\section{Список литературы}

[1] A.N. Aleshin. Adv. Materials, 18, 17 (2006).

[2] J. Huang. Pure Appl. Chem., 78 (1), 15 (2006).

[3] S.R. Sivakkumar, W.J. Kim, J.A. Choi, D.R. Mac Farlane, M. Forsyth, D.W. Kim. J. Power Sources, 171 (2), 1062 (2007).

[4] A.Z. Sadek, W. Wlodarski, K. Kalantar-Zadeh, C. Baker, R.B. Kaner. Sensors Actuators A: Physical, 139 (1), 53 (2007).

[5] M.Y. Chang, C.S. Wu, Y.F. Chen, B.Z. Hsieh, W.Y. Huang, K.S. Ho, Y.K. Han. Organic Electron., 9 (6), 1136 (2008).

[6] C.O. Baker, Xinwei Huang, W. Nelson, R. B. Kaner. Chem. Soc. Rev., 46 (5), 1510 (2017).

[7] M. Delvaux, J. Duchet, P.Y. Stavaux, R. Legras, S. DemoustierChampagne. Synt. Metals, 113 (3), 275 (2000).

[8] J. Stejskal, I. Sapurina, J. Prokeš, J. Zemek. Synt. Metals, 105 (3), 195 (1999).

[9] I. Sapurina, A. Riede, J. Stejskal. Synt. Metals, 123 (3), 503 (2001).

[10] М.А. Шишов, В.А. Мошников, И.Ю. Сапурина. ЖПХ, 86 (1), 56 (2013).

[11] И.Ю. Сапурина. Автореф. докт. дис. (СПб., ИВС РАН, 2015).

[12] M. Schnippering, H.V. Powell, S.R. Mackenzie, P.R. Unwin. J. Phys. Chem. C, 113 (47), 20221 (2009).

[13] Б.И. Шкловский, А.Л. Эфрос. Электронные свойства легированных полупроводников (М., Наука, 1979) гл. 5.

Редактор А.Н. Смирнов

\section{The change of polyaniline nanotubes conductivity during formation}

\author{
V.M. Kapralova1 , I.Yu. Sapurina ${ }^{2}$, N.T. Sudar ${ }^{1}$ \\ ${ }^{1}$ Peter the Great St. Petersburg Polytechnic University, \\ 195251 St. Petersburg, Russia \\ 2 Institute of macromolecular compounds, \\ Russian Academy of Sciences, \\ 199004 St. Petersburg, Russia
}

Abstract A method to form conducting polyaniline nanotubes based on direct polymerization of aniline on the surface of channels in track membranes has been shown to be applicable for the production of nanotubes with assigned conductivity. It is found that island-type film is formed at the initial stage of polymerization, so the average resistance for single channel is high, reaching $\sim 10^{19} \Omega$. The duration of the initial stage is about $2 \mathrm{~min}$. An increase of polymerization time to 3 min leads to decrease of the channel resistance by more than 10 orders. It is supposed that the step of resistance is due to the formation of continual film on the track channel surface. When the polymerization time is increased further, the channel resistance declines gradually to $\sim 10^{7}$ for the time value of $10 \mathrm{~min}$. The specific conductivity of continual polyaniline film grown on the track channel surface is evaluated. It equals to $0.01-0.04 \mathrm{~S} / \mathrm{cm}$ if hollow tubes are formed and increases up to $\sim 0.2 \mathrm{~S} / \mathrm{cm}$ when the track channels are completely filled with polyaniline. 